\title{
Study of management on comorbid conditions in type-2 diabetes mellitus.
}

\author{
Arun Kumar S*, Subba Rao Ch, Priyanka D \\ Department of Pharmacy Practice, Vaageswari College of Pharmacy, Karimnagar, JNTUH, India
}

\begin{abstract}
Diabetes mellitus is a group of metabolic disorders characterized by hyperglycemia; is associated with abnormalities in carbohydrates, fat, and protein metabolism; and results in chronic complications including microvascular, macrovascular, and neuropathic disorders. The long term complications include retinopathy with potential blindness, nephropathy with kidney failure and neuropathy with risk of foot ulcers, amputation, and Charcot joint and sexual dysfunction. Macrovascular event is responsible for $75 \%$ of deaths in patients having type-2 DM. Multiple risk factors are responsible for developing type-2 DM, which include family history, obesity, habitual physical activity, race or ethnicity, previously identified impaired glucose tolerance or impaired fasting glucose, hypertension, high density lipoprotein cholesterol and triglyceride. This study is done to manage the comorbid conditions of diabetes mellitus. This study is a prospective observational study which was conducted over a period of 6 months among type-2 diabetic patients attending at an out-patient department of Care Diabetes Center, Hanamakonda, Warangal, Andhra Pradesh. This study took place between March and September 2013. Collected all relevant information from the patient's case sheets, laboratory reports, patients care taker, treatment charts and counseling. All the collected information documented properly by data collection form. Out of 554 patients was enrolled into the study. Among them $252(45.48 \%)$ of these patients were men and $302(54.52 \%)$ were females respectively. $58.48 \%$ (324) were associated with macrovascular complications and $33.39 \%$ (185) were associated with microvascular complications. This study was conducted to increase prevalence of disease, through creating awareness about drug treatment and diabetic complications. Among the various complications, macrovascular complications caused major threat and among macrovascular complications, Hyperlipidemia and hypertension are major causes. Prophylaxis was done for patient's inorder to prevent the further complication of diabetes mellitus.
\end{abstract}

Keywords: Diabetes mellitus, Macrovascular complications, Microvascular complications.

Accepted on March 29, 2018

\section{Introduction}

According to WHO (World Health Organization) 2006, Diabetes mellitus is defined as metabolic disorder of multiple etiology characterized by chronic hyperglycemia with disturbances of carbohydrate, protein and fat metabolism resulting from defect in insulin secretion, insulin action or both.

Diabetes mellitus is a group of metabolic disorders characterized by hyperglycemia; is associated with abnormalities in carbohydrates, fat, and protein metabolism; and results in chronic complications including microvascular, macrovascular, and neuropathic disorders. The effects of diabetes mellitus include long-term damage, dysfunction and failure of various organs. This is also having characteristic symptoms like thirsty, polyuria, blurring of vision and weight loss. The long term complications include retinopathy with potential blindness, nephropathy with kidney failure and neuropathy with risk of foot ulcers, amputation, and Charcot joint and sexual dysfunction (American Diabetes Association [1]. Macrovascular event is responsible for $75 \%$ of deaths in patients having type- 2 DM. Multiple risk factors are responsible for developing type-2 DM, which include family history, obesity, habitual physical activity, race or ethnicity, previously identified impaired glucose tolerance or impaired fasting glucose, hypertension, high density lipoprotein cholesterol and triglyceride. Researchers have shown that as a result of these complications, the quality of life (QOL) of patients with type-2 DM is remarkably lower than the QOL of general population and also somewhat lower than patients with other chronic disease. Most complications are preventable and a key strategy is metabolic control through of diet, exercise, and medication (Ruth, et al., 2008).

Nearly $10-15 \%$ of patients suffers from type-1 diabetes. It usually occurs in younger population, below 30 years of age. Occurring of type-1 diabetes is very high in girls between 10 12 years of age and boys between 12-14 years of age. Type-2 diabetes occurs mainly in older population $>40$ years of age. Most commonly occur in 55 years of age [2]. According to World Health Organization (WHO), there are 31.7 million people in India were affected by diabetes during the year 2000 which may further rise to 79.4 million by the year 2030. There are 171 million people in the world with diabetes in the year 2000 and it has estimated to increase 366 million by 2030 [3].

\section{Aim and Objective of the Work}

\section{Aim}

Main aim of this study is to treat co-morbid conditions which are associated with type-2 DM. 
Citation: Arun KS, Subba Rao C, Priyanka D. Study of management on comorbid conditions in type-2 diabetes mellitus. Adv Cell Sci Tissue Cult. 2018;2(1):5-11

\section{Objective}

- To identify common complications in type-2 DM patients.

- To identify commonly used or prescribed medications to manage complications.

- To identify prophylaxis prescribed medications to prevent complications.

\section{Methodology}

This study is a prospective observational study which was conducted over a period of 6 months among type- 2 diabetic patients attending at out-patient department of Care Diabetes Center, Hanamakonda, Warangal, Andhra Pradesh [4-6]. This study took place between March and September 2013. During the study period, the patients visiting out-patient department of care diabetes center were reviewed into the study by considering following inclusion and exclusion.

\section{Inclusion criteria}

- Type-2 Diabetic patients of both Genders.

- Patients of more than or equal to 20 years of age.

- Type-2 Diabetic patients having at least one diabetic complication.

\section{Exclusion criteria}

- Gestational Diabetes.

- Patients with Type-1 Diabetes.

Collected all relevant information from the patient's case sheets, laboratory reports, patients care taker, treatment charts and counseling. All the collected information documented properly by data collection form.

a) Demographic details: Age, sex, education and address.

b) Past medical history and present medical history.

c) Habits: Type of diet, smoking, alcohol consumption

d) Comorbid conditions

e) Body mass index (BMI)

f) Laboratory findings: Hemogram, serum biochemistry, blood pressure, lipid profile.

g) Radiological findings: Vascular test, ECG, Foot examination, Fundus examination, CT, MRI, Micral test, Neuropathy.

BMI calculation is a standardized method to quantify the degree of obesity in an individual based on an individual's height and weight. It is also called Quetelet Index.

$$
\text { BMI }=\frac{\text { Weight }(\mathrm{kg})}{\text { Height }(\mathrm{m})^{2}}
$$

The patients are categorized into 3 categories based on their BMI score as:
i. $\quad \mathrm{BMI} \leq 18.5$ as underweight
ii. $\quad \mathrm{BMI} \geq 18.5, \leq 25$ as normal weight
iii. $\quad B M I \geq 25$ as overweight.

\section{Statistical analysis}

- Microsoft-Excel was used for standard deviation.

\section{Results}

During the study period (March-September 2013) total 2000 patients were reviewed. Among them, total number of 554 patients was enrolled into the study. Among them 252 (45.48\%) of these patients were men and $302(54.52 \%)$ were females respectively (Table 1).

\section{Age wise distribution of patients}

More number of patients were in the age group between 50-59 years $(31.40 \%)$ followed by age group $40-49$ years $(29.06 \%)$. Both the age groups females are higher than males (Table 2).

\section{Diabetic patients with comorbid conditions}

Out of 554 patients nearly $58.48 \%$ (324) were associated with macrovascular complications like hypertension, Ischemic heart disease and Hyper lipidemia and 33.39\% (185) were associated with microvascular complications like Neuropathy, Nephropathy and Retinopathy. Diabetic foot ulcers are not present. Remaining $8.13 \%$ (45) were associated with other complications like Asthama, Hypothyroidism etc. Among them macrovascular complications are most predominant (Table 3 and Figure 1).

\section{Details of macrovascular diabetic complications}

Macrovascular complications which are associated with diabetes are Hypertension (57.22\%), Ischemic heart disease (21.66\%), Hyperlipidemia (47.65\%). Hypertension is the highest percent among the macrovascular complications (Table 4).

Table 1: Gender wise distribution of patients.

\begin{tabular}{|c|c|c|}
\hline Gender distribution & Number of patients & Percentage (\%) \\
\hline Males & 252 & 45.48 \\
\hline Females & 302 & 54.52 \\
\hline Total $(\mathrm{n})$ & 554 & 100 \\
\hline$n=$ Total number of patients & & \\
\hline
\end{tabular}

Table 2: Age wise distribution of patients.

\begin{tabular}{|c|c|c|c|c|c|c|}
\hline $\begin{array}{c}\text { Age } \\
\text { group } \\
\text { (years) }\end{array}$ & $\begin{array}{c}\text { Total } \\
\text { no of } \\
\text { patients }\end{array}$ & Males & Females & $\begin{array}{c}\text { Total no of } \\
\text { patients (\%) }\end{array}$ & Males (\%) & $\begin{array}{c}\text { Females } \\
\text { (\%) }\end{array}$ \\
\hline $20-29$ & 12 & 7 & 5 & 2.16 & 1.26 & 0.90 \\
\hline $30-39$ & 57 & 29 & 28 & 10.28 & 5.23 & 5.05 \\
\hline $40-49$ & 161 & 62 & 99 & 29.06 & 11.19 & 17.87 \\
\hline $50-59$ & 174 & 67 & 107 & 31.40 & 12.09 & 19.31 \\
\hline $60-69$ & 127 & 63 & 64 & 22.92 & 11.37 & 11.55 \\
\hline$>70$ & 23 & 13 & 10 & 4.15 & 2.34 & 1.81 \\
\hline
\end{tabular}

Age wise distribution of patients and their percentage females are more than male, more number of patients were in the age group 50-59 years.

Table 3:-Diabetic patients with co-morbid conditions.

\begin{tabular}{|c|c|c|}
\hline Co-morbid conditions & No of patients & Percentage (\%) \\
\hline Macrovascular complications & 324 & 58.48 \\
\hline Microvascular complications & 185 & 33.39 \\
\hline Other complications & 45 & 8.12 \\
\hline
\end{tabular}

Macrovascular complications with microvascular complications are more when compared. 


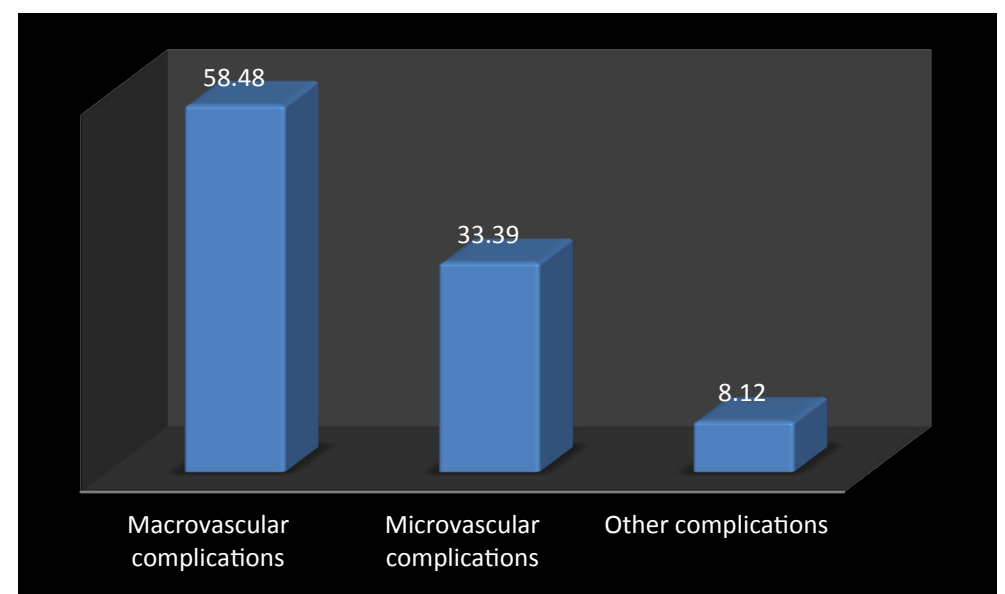

Figure 1. Percentage of diabetic patients with co-morbid conditions. Macrovascular complications with microvascular complications are more when compared.

\section{Drug therapy of DM patients with HTN}

Most commonly prescribed combination therapy of drugs for treating hypertension were Olmesartan and hydrochlorthiazide $(46.68 \%)$ followed by telmisartan and hydrochlorthiazide $(5.67 \%)$ which are angiotensin receptor blockers and thiazides diuretics [7-12]. Monotherapy of drugs are telmisartan (17.66\%) followed by losartan (17.35\%) angiotensin receptor blockers are prescribed more. Metaprolol (9.46\%) beta-blocker, Amlodipine (1.57\%) calcium channel blocker, Ramipril (0.94\%) and Enalapril (0.63\%) which are angiotensinogen converting enzyme are prescribed $[13,14]$. The treatment have analysed that the class of angiotensin receptor blocker along with thiazides diuretic are prescribed most commonly (Figure 2 and Table 5).

\section{Drug therapy of DM patients with IHD}

Most commonly prescribed drugs are in the class of anti-platelets are Aspirin (35.83\%) were given to the patients with ischemic heart disease followed by clopidogrel (32.5\%). A combination of aspirin and clopidogrel $(2.5 \%)$ were given to coronary heart disease patients, which shows synergistic effect. A combination of aspirin and Atorvastatin (29.16\%) were prescribed to elevated LDL cholesterol patients (Figure 3 and Table 6).

\section{Drug therapy of DM patients with hyperlipidemia}

Patients with elevated total cholesterol or LDL cholesterol were given Atorvastatin (72.72\%). Fenofibrates were given to patients with elevated triglycerides [15-18]. Rosuvastatin $(21.21 \%)$ were given to reduce HDL. Combination therapy was given more rarely. Atorvastatin and fenofibrate $(0.37 \%)$ given to the patients with both elevated triglycerides and LDL cholesterol. Rosuvastatin and fenofibrate (5.68\%) were given to the patients with both elevated triglyceride and reduce HDL (Figure 4 and Table 7).

\section{Details of microvascular diabetic complications}

Micro vascular complications occur due to the damage of small blood vessels. Damage of nerves from diabetes is known as diabetic neuropathy $(67.76 \%)$. Nephropathy, where kidney enlarges in size, which follows the increase in glomerular filtration rate (GFR), but as the disease advances it decreases $(2.88 \%)$. Diabetic Retinopathy affects the eyes, risk of
Table 4: Details of different macrovascular diabetic complications.

\begin{tabular}{|c|c|}
\hline Macrovascular complications & Percentage (\%) \\
\hline Hypertension & 57.22 \\
\hline Ischemic heart disease & 21.66 \\
\hline Hyperlipidemia & 47.65 \\
\hline Diabetic macrovascular complications and their percentage. \\
\hline
\end{tabular}

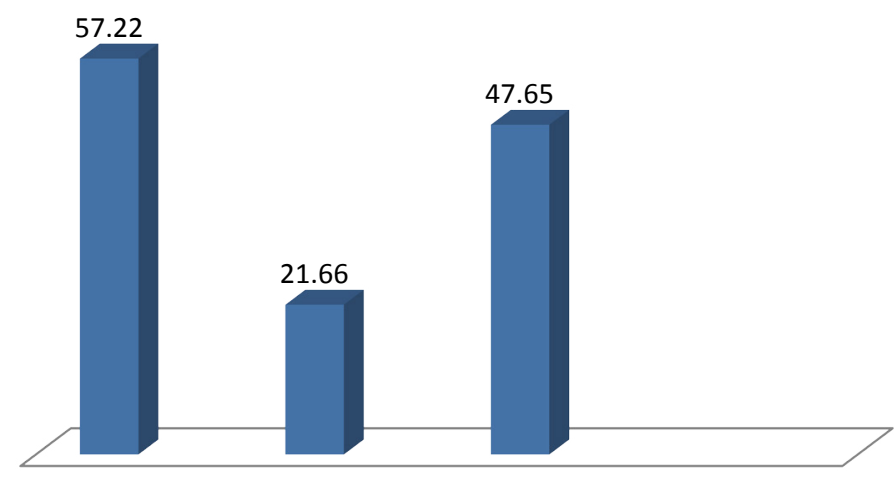

Hypertension Ischemic heart disease Hyperlipidemia

Figure 2. Percentage of different macrovascular diabetic complications. Hypertension is more occurring complication with diabetes mellitus followed by hyperlipidemia.

Table 5: Details of different drugs used in therapy of DM patients with $\operatorname{HTN}(n=317)$.

\begin{tabular}{|c|c|}
\hline Drugs used in therapy of HTN & Percentage (\%) \\
\hline Losartan & $17.35 \%$ \\
\hline Telmisartan & $17.66 \%$ \\
\hline Metaprolol & $9.46 \%$ \\
\hline Olmesartan+hydrochlorthiazide & $46.68 \%$ \\
\hline Telmisartan+hydrochlorthiazide & $5.67 \%$ \\
\hline Amlodipine & $1.57 \%$ \\
\hline Enalapril & $0.63 \%$ \\
\hline Ramipril & $0.94 \%$ \\
\hline
\end{tabular}

$n=$ total no of patients. Class of drugs, Angiotensin receptor blockers and thiazides diuretics are prescribed more (Olmesartan+hydrochlorthiazide).

developing diabetic retinopathy $(4.51 \%)$ or other microvascular complications of diabetes depends on both the duration and the severity of hyperglycemia (Figure 5 and Table 8).

\section{Drug therapy of DM patients with nephropathy}

Nephropathy associated with Diabetes mellitus $[19,20]$. 
Citation: Arun KS, Subba Rao C, Priyanka D. Study of management on comorbid conditions in type-2 diabetes mellitus. Adv Cell Sci Tissue Cult. 2018;2(1):5-11

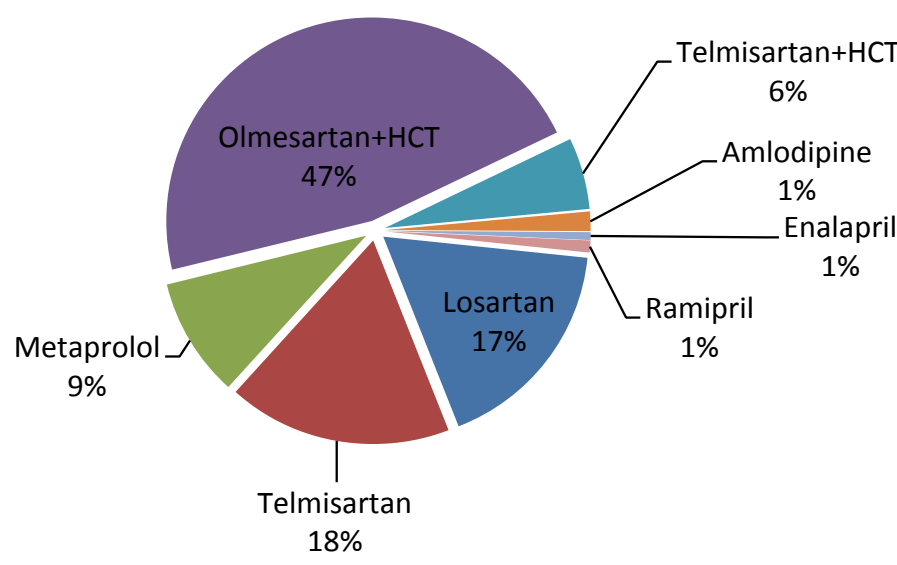

Figure 3. Percentage of different drugs used in therapy of DM patients with HTN. Olmesartan $+H C T$ (hydrochlorthiazide) drugs are prescribed more followed by losartan.

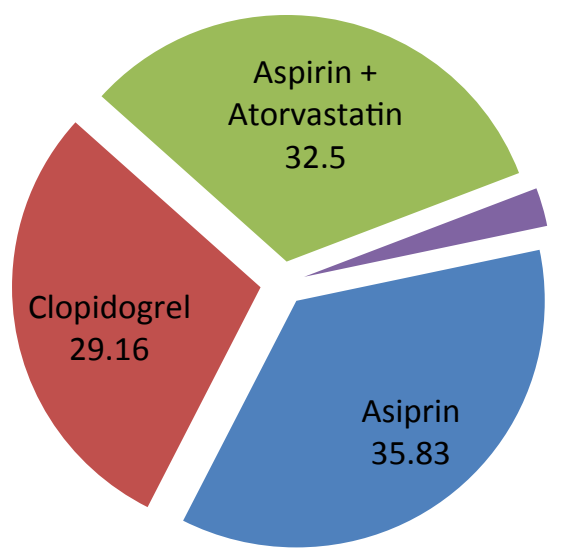

Aspirin

+ Clopidogrel

2.5

Figure 4. Percentage of different drugs used in therapy of DM patients with IHD percentage of anti-platelets drugs prescribed. Aspirin were prescribed more when compared with other drug.

Table 6: Details of different drugs used in therapy of DM patients with IHD $(n=120)$.

\begin{tabular}{|c|c|}
\hline Drugs used in therapy of IHD & Percentage (\%) \\
\hline Aspirin & $35.83 \%$ \\
\hline Clopidogrel & $32.5 \%$ \\
\hline Aspirin+Atorvastatin & $29.16 \%$ \\
\hline Aspirin+Clopidogrel & $2.5 \%$ \\
\hline
\end{tabular}

$n=t o t a l$ no of patients. IHD drugs associated with diabetes. Class of anti-platelets drugs.

Table 7: Details of drugs used in therapy of DM patients with Hyperlipidemia $(n=264)$.

\begin{tabular}{|c|c|}
\hline Drugs used in therapy of Hyperlipidemia & Percentage (\%) \\
\hline Atorvastatin & $72.72 \%$ \\
\hline Rosuvastatin & $21.21 \%$ \\
\hline Atorvastatin+Fenofibrate & $0.37 \%$ \\
\hline Rosuvastatin+Fenofibrate & $5.68 \%$ \\
\hline
\end{tabular}

$n=t o t a l$ no of patients. Hyperlipidemia drugs, Statins (HMG COA reductase inhibitors).

Where kidney enlarges in size, which follows the increase in glomerular filtration rate (GFR), but as the disease advances it decreases. Class of drugs such as angiotensin converting enzyme inhibitors, angiotensin receptor blockers and diuretics were given in diabetic nephropathy. Losartan (56.25\%) were given mostly followed by torsemide $(25.00 \%)$ and Ramipril (18.75\%) (Figure 6 and Table 9).

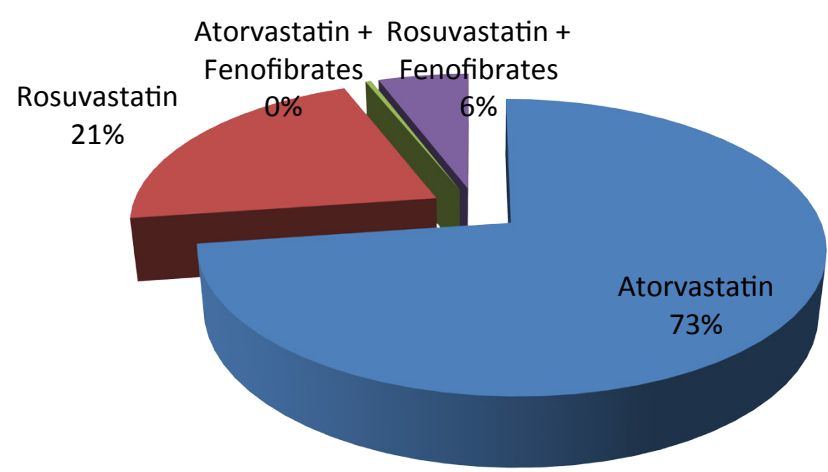

Figure 5. Percentage of different drugs used in therapy of DM patients with hyperlipidemia. Percentage of statins prescribed to reduce cholesterol. Atorvastatin preferred more.

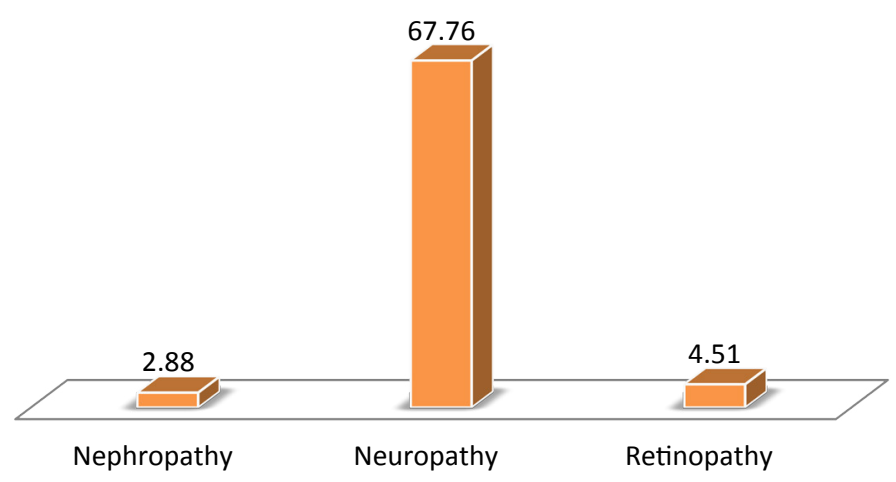

Figure 6. Details of different microvascular diabetic complications. Among microvascular complications, Neuropathy is most leading complication.

Table 8:-Details of different microvascular Diabetic Complications.

\begin{tabular}{|c|c|}
\hline Microvascular complications & Percentage (\%) \\
\hline Nephropathy & 2.88 \\
\hline Neuropathy & 67.76 \\
\hline Retinopathy & 4.51 \\
\hline Diabetic microvascular complications and their percentage. \\
\hline
\end{tabular}

Table 9: Details of different drugs used in therapy of DM patients with Nephropathy. $(n=16)$.

\begin{tabular}{|c|c|}
\hline Nephropathy & Percentage (\%) \\
\hline Ramipril & 18.75 \\
\hline Losartan & 56.25 \\
\hline Torsemide & 25.00 \\
\hline
\end{tabular}

\section{Drug therapy of DM patients with neuropathy}

Damage of nerves from diabetes is known as diabetic neuropathy. In diabetic neuropathy NSAIDS were prescribed more acetaminophen $(45.06 \%)$ followed by anti-convulsants, pregabalin $(25.6 \%)$, Clonazepam $(11.46 \%)$ which is a sedative, beta-histine $(6.4 \%)$ an anti-vertigo drug, Famotidine (3.73\%) $\mathrm{H}_{2}$-receptor antagonist, Amitriptyline (3.2\%) anti-depressant, Acyclopram+Clonazepam (2.93\%), Duloxetine (1.6\%) (Figure 7).

Anti-depressants and anti-convulsants are given as first line therapy in diabetic neuropathy.

Details of drugs used for prophylaxis of HTN and hyperlipidemia

Prophylaxis is a prevention of disease and possible health issues. 
In macrovascular complications, HTN drugs are prescribed more commonly [21-23]. Olmesartan $10 \mathrm{mg}$ (38.96\%), Losartan (33.76\%), Telmisartan $10 \mathrm{mg}$ and $20 \mathrm{mg}$ (7.79\%), Metaprolol succinate $12.5 \mathrm{mg}(7.79 \%)$, Telmisartan+Amlodipine $(20+2.5$ $\mathrm{mg}$ ), Enalapril $5 \mathrm{mg}$ (1.29\%), Cilindipine $5 \mathrm{mg}$ (1.29\%).

Class of drugs: angiotensin receptor blockers are prescribed more followed by beta-blockers.

Hyperlipidemia drugs are prescribed more common after HTN drugs. Atorvastatin $10 \mathrm{mg}(83.92 \%)$ were given for maximum members, Rosuvastatin $10 \mathrm{mg}$ (14.28\%), Colestipol $5 \mathrm{mg}$ (1.78\%) (Figures 8-10 and Tables 10-12).

\section{Discussion}

In this study, Diabetes Mellitus associated comorbid conditions were analyzed and managed by the treatment. Type- 2 DM is a complex, heterogeneous, polygenic metabolic syndrome where the body fails to produce enough insulin which is required for our body, characterized by abnormal homeostasis [24-26]. The burden of DM is sever with macrovascular complications like HTN, peripheral vascular disease, atherosclerosis and microvascular complications like nephropathy, neuropathy, retinopathy of the disease. Result of ageing, increasing obesity and decreasing physical activity, the global incidence of prevalence of DM exploding.

In this study, total number of 554 Type-2 Diabetes Mellitus patients prescriptions was included, were females $(54.52 \%)$ are

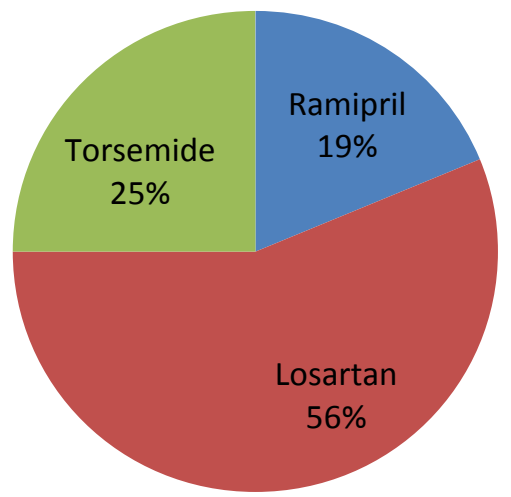

Figure 7. Percentage of different drugs used in therapy of nephropathy. Percentage of drugs used to reduce complications of nephropathy. Losartan prescribed more.

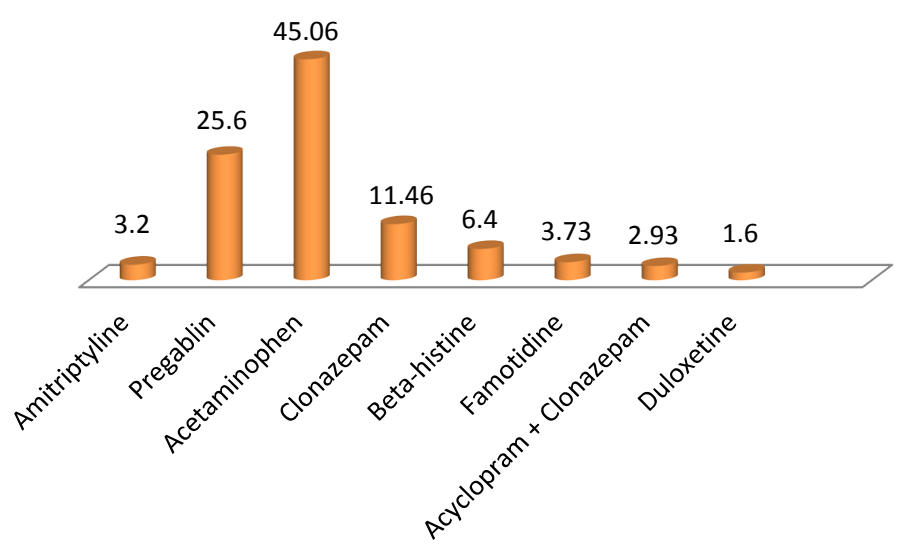

Figure 8. Percentage of different drugs used in therapy of Neuropathy. Percentage of drugs used to reduce neuropathic complications.

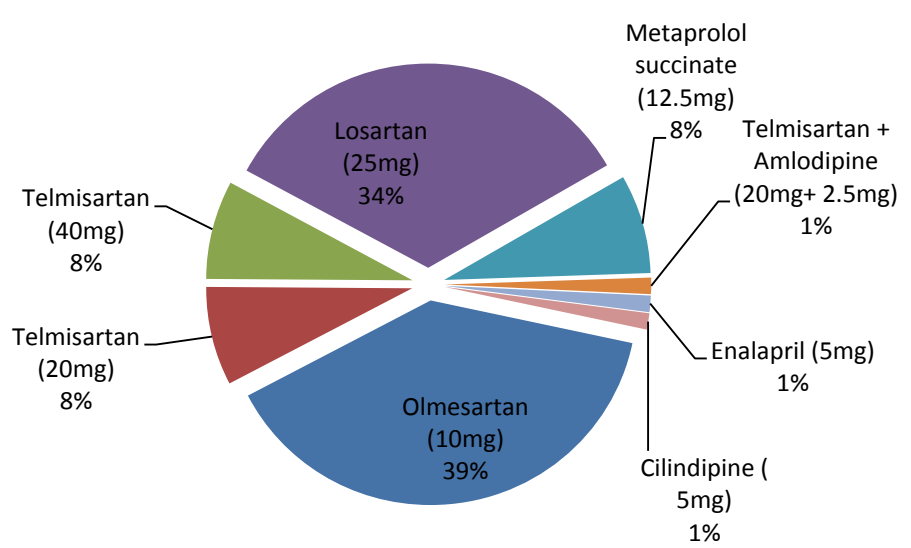

Figure 9. Percentage of drugs used in prophylaxis of HTN.

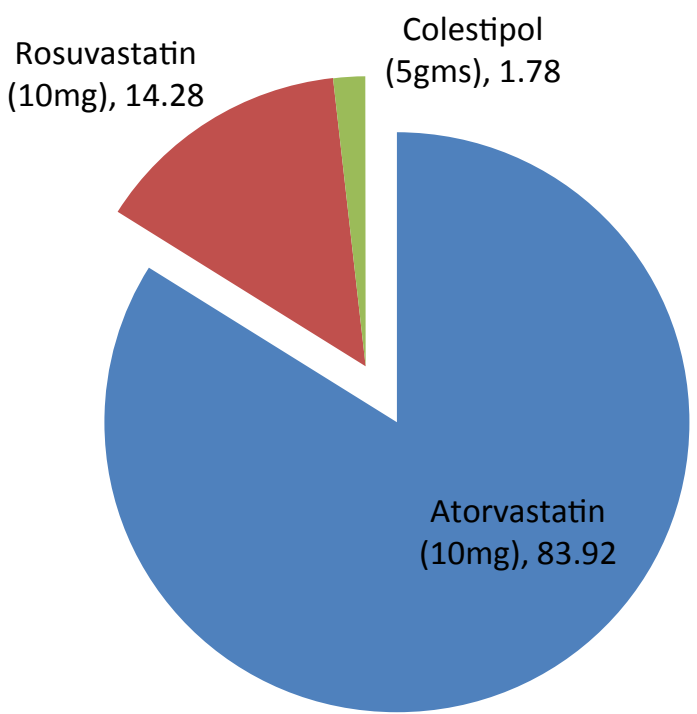

Figure 10. Percentage of drugs used in prophylaxis of hyperlipidaemia.

higher than males $(45.48 \%)$ same as percentage of females were more than men when compared with the previous study $[27,28]$. It was observed that maximum number of patients $(31.40 \%)$ were between age group of 50-59 years same as compared with previous study [3]. In generally elder patients are at a greater risk of developing Type-2 Diabetes Mellitus.

Diabetes complications are major life threatening, which leads to morbidity and mortality. Patients with long duration of Diabetes are at high risk of developing complications [29,30]. Various Macrovascular complications including Hypertension, Hyperlipidemia, and Ischemic heart disease, cardiovascular complications cause major threat. In this study there were total number of 554 patients prescriptions were enrolled. Macrovascular complications are found to be in more percentage $(58.48 \%)$ when compared to Microvascular complications. Among Macrovascular complications, Hypertension was accounted for $57.22 \%$ of the total complications in diabetes patients, highest percentage of complications followed by Hyperlipidemia. Same results were obtained by previous studies $[4,5]$.

ARB's and thiazides diuretics are given in combination for treating HTN (46.68\%) followed by ARB's (17.66\%). Patients with elevated total cholesterol or LDL cholesterol were given Atorvastatin. Fenofibrates were given to patients with elevated 
Citation: Arun KS, Subba Rao C, Priyanka D. Study of management on comorbid conditions in type-2 diabetes mellitus. Adv Cell Sci Tissue Cult. 2018;2(1):5-11

Table 10: Details drugs of different used in therapy of DM patients with Neuropathy $(n=375)$.

\begin{tabular}{|c|c|}
\hline Neuropathy & Percentage (\%) \\
\hline Amitriptyline & 3.2 \\
\hline Pregabalin & 25.6 \\
\hline Acetaminophen & 45.06 \\
\hline Clonazepam & 11.46 \\
\hline B-histine & 6.4 \\
\hline Famotidine & 3.73 \\
\hline Acyclopram+Clonazepam & 2.93 \\
\hline Duloxetine HCL & 1.6 \\
\hline
\end{tabular}

$n=n o$ of patients. Neuropathic drugs, mostly prescribed drugs are NSAIDS followed by anti-convulsants.

Table 11: Drugs used for prophylaxis of HTN.

\begin{tabular}{|c|c|c|}
\hline Hypertension & $\begin{array}{c}\text { No. of } \\
\text { patients }\end{array}$ & Percentage (\%) \\
\hline Olmesartan (10 $\mathrm{mg})$ & 30 & 38.96 \\
\hline Telmisartan $(20 \mathrm{mg})$ & 6 & 7.79 \\
\hline Telmisartan $(40 \mathrm{mg})$ & 6 & 7.79 \\
\hline Losartan $(25 \mathrm{mg})$ & 26 & 33.76 \\
\hline Metaprolol succinate $(12.5 \mathrm{mg})$ & 6 & 7.79 \\
\hline Telmisartan+Amlodipine $(20 \mathrm{mg}+2.5 \mathrm{mg})$ & 1 & 1.29 \\
\hline Enalapril $(5 \mathrm{mg})$ & 1 & 1.29 \\
\hline Cilindipine $(5 \mathrm{mg})$ & 1 & 1.29 \\
\hline
\end{tabular}

Table 12: Drugs used for prophylaxis of Hyperlipidemia.

\begin{tabular}{|c|c|c|}
\hline Hyperlipidemia & Total number of patients & Percentage (\%) \\
\hline Atorvastatin $(10 \mathrm{mg})$ & 47 & 83.92 \\
\hline Rosuvastatin $(10 \mathrm{mg})$ & 8 & 14.28 \\
\hline Colestipol $(5 \mathrm{gms})$ & 1 & 1.78 \\
\hline
\end{tabular}

triglycerides. Rosuvastatin were given to reduce HDL. Statins (72.72\%), HMG CoA reductase inhibitors many acts on abnormal lipid levels and atherosclerotic plaque stabilizing effect. Aspirin $(35.83 \%)$, an anti platelet drug used to treat patients with coexisting IHD. Clopidogrel was given to patients with acid peptic disease. Combination therapy of aspirin and clopidogrel given to patients with coronary artery disease. Ramipril, Aspirin and Atorvastatin were given to patients with associated HTN, IHD and Hyperlipidemia.

Microvascular complications which include neuropathy, nephropathy and retinopathy. Out of 554 patients prescriptions, Microvascular complications were found to be 185 patients the percentage of patients who are diagnosed with diabetic nephropathy are $2.88 \%$, diabetic neuropathy are $67.76 \%$, diabetic retinopathy are found to be $4.51 \%$. Among these complications diabetic neuropathy was higher when compared to diabetic nephropathy and diabetic retinopathy. Hence diabetic neuropathy is more common in Warangal and karimnagar regions. When compared with study diabetic nephropathy is more may be due to life style, food habits etc.

In treatment of diabetic neuropathy NSAID's were prescribed common (45.06\%); Acetaminophen. Followed by Anti convulsants (25.6\%); pregabalin and sedative (11.46\%); Clonazepam. In treatment of diabetic nephropathy ARB's are most commonly prescribed drugs $(56.25 \%)$, followed by diuretics $(25.00 \%)$.

Prophylaxes of Diabetes Mellitus patients with HTN were treated, according to JNC $7^{\text {th }}$ Guidelines if BP is $\leq 130 / 80$. ARB's are given for HTN (38.96\%); Olmesartan $10 \mathrm{mg}$ followed by losartan $10 \mathrm{mg}$ (33.78\%). For Hyperlipidemia, Atorvastatin 10 $\mathrm{mg}(83.92 \%)$ followed by $(14.28 \%)$.

\section{Conclusion}

In this study, Diabetes Mellitus associated comorbid conditions were analyzed and managed by the treatment. This study shows the drug utilization pattern of co-morbidities among type- 2 diabetic patients which were conducted in out-patient department. In this study females were more affected than males. It was observed that maximum number of patients $(31.40 \%)$ was between age group of 50-59 years.

This study was conducted to increase prevalence of disease, through creating awareness about drug treatment and diabetic complications. Among the various complications, macrovascular complications caused major threat and among macrovascular complications, Hyperlipidemia and hypertension are major causes. Prophylaxis was done for patients in order to prevent the complication of diabetes mellitus.

\section{References}

1. American Diabetes Association. Standards of medical care in diabetes. Diabetes Care. 2013;36(1):1-66.

2. Wild S, Roglic G, Green A, et al. Global Prevalence of Diabetes: Estimation for the year 2000 and projections for 2030. Diabetes Care. 2004;27:1047-53.

3. Akila L, Sandozi T, Geetha Devi, et al. Drug utilization study on oral anti-diabetic drugs at a tertiary care (SRM Medical college) hospital in Chennai, Int J Med Research. 2011;1(3):177-82.

4. Upadhyay DK, palaian S, Shankar RP, et al. Prescribing pattern in diabetic out patients in a tertiary care teaching hospital in Nepal. Journal of Clinical and Diagnostic Research. 2007;3;248-55.

5. Arshad K, Kumar SA. Study on Drug Utilization of Oral Hypoglycemic Agents in Type-2 DM Patients. Asian J Pharm Clin Res. 2011;4(4):60-4.

6. Howlett JG, Macfadyen JC. Treatment of Diabetes in people with Heart Failure. Canadian Diabeties Association Clinical Practice Guideline Expert Committee. Can J Diabeties. 2013;37:126-8.

7. Kamrai D. Sachdeva P. Prescribing Trends of Antidiabetics in Diabetic Patients and Hypertensive Diabetic Patients in an Urban Secondary Care Hospital. IJPBA. 2010;1(3):249-55.

8. Lindsay TJ. Vitrikas K., Temporal-M, et al. Herndon CM. Diabetic Neuropathic Pain: Real World Treatment Options. Clinical Medicine Insights: Therapeutics. 2012;4:169-83.

9. Morerai RO. Papelbaum M, Fontenelle LF, et al. Comorbidity of psychiatric disorders and symmetric distal polyneuropathy among Type-2 Diabetic Outpatients. Braz J Med Biol Res. 2007;40(2):269-75.

10. Motataianu A. Stoian A. Bajko Z. Diabetic Cardiovascular Autonomic Neuropathy Clinical impact-Acta. Medica. Transilvanica March. 2013;2(1):315-18. 
11. Nwabudike LC, Tirgoviste CI. Risk Factors and Clinical characteristics for foot ulcers in Patients with Diabetes in Bucharest. Romania. Proc Rom Acad. 2008;1(2):49-52.

12. NICE Clinical guideline 87 - type 2 diabetes.

13. Patel B, Oza B, Patel KP, et al. Patten: of anti-diabetic drugs use in type 2 diabetic patients in a medicine outpatient clinic of tertiary care teaching hospital, Int J Basic Clin Pharmacol Aug. 2013;(40):485-91.

14. Rema M, Pradeepa $\mathrm{R}$, diabetic retinopathy :An Indian perspective Indian J Med Res March. 2007;125:297-10.

15. Rohilla A, Kumar R, Rohilla S, et al. Diabetic Retinopathy: origin and complications. Euro J Exp Bio. 2012-310.

16. Ruthu K, Anneli R, Margous L. Predators of quality of life of patients with type 2 diabeties. Patients Preferences and Adherence. 2008;2:21-6.

17. Subbasish S, koushik DK, Sabita S, et al. Prescription analysis in diabetes mellitus. Int $\mathrm{J}$ Pharm Bio Sci. 2010;1(1):1-8.

18. Sumanth Bala, Soundarssanane M, Gautham R, e al. Risk factors of Diabetes mellitus in Rural puducherry. Online Journal of Health and Allied Sciences. 2012;11(1).

19. Standards of Medical Care and Diabetes Care. 2010;33:11-61.

20. Boccuzzi SJ. Utilization of oral hypoglycemic agents in a drug insured U.S population. Diabeties Care. 2001;24(8):1411-15.
21. Lindsay TJ, Vitrikas K, Temporal M, et al. Diabetic neuropathic pain: real world treatment options. Clinical; Medicine Insights: Therapeutics. 2012;4:169-83.

22. Katon WJ. The association of comorbid depression with mortality in patients with type-2 diabetes. Diabetes Care. 2005;28:2668-72.

23. Winaver J, Teredesai P, Feldman HA. Diabetic nephropathy as the mode of presentation of diabetes mellitus. Metab Clin Exp. 1979;28:1023-30.

24. Abate N, Chandalia M. Ethnicity and type-2 diabetes focus on Asian Indians. Journal of Diabetes and its Complications. 2001;15:320-27.

25. Ali N. Analysis of drug used for the treatment of complications of diabetes in a teaching hospital der. Pharmacia Letter. 2011;3(4):163-77.

26. American Diabetes Association. Treatment of hypertension in adults with diabetes. Diabetes Care. 2002;25;71-73.

27. American Diabetes Association. Economic cost of diabetes in the US in 2002. Diabetic Care. 2003;26:917-32.

28. American Diabetes association. Standards of medical care in diabetes. Diabetes Care. 2007;30(1):4-41.

29. Boulton AJM. Management of diabetic peripheral neuropathy. Clinical Diabetes. 2005;23(1):9-15.

30. Boulton AJM, et al. Neuropathic diabetic foot ulcers. N Engl J Med. 2004;351:48-55.

\section{*Correspondence to:}

Arun KS

Department of Pharmacy Practice

Vaageswari College of Pharmacy

India

Tel: 09502588612

E-mail: chamakurii.subbu@gmail.com 